\title{
Acceleration-based disturbance compensation for elastic rack-and-pinion drives
}

\author{
Felix Brenner $^{1}$ (D) Armin Lechler $^{1} \cdot$ Alexander Verl $^{1}$
}

Received: 7 May 2021 / Accepted: 5 July 2021 / Published online: 19 July 2021

(c) The Author(s) 2021

\begin{abstract}
Rack-and-pinion drives are mainly used for large machine tools and are often operated with indirect position control. Due to the lack of state information on the output side, this results in reduced accuracy regarding the table position. In addition, the system can only react inadequately to disturbances outside the control loop, meaning that often insufficient results can be achieved in typical application scenarios such as milling. To meet the increasing dynamic and accuracy requirements of the modern manufacturing industry, this paper presents a highly dynamic acceleration-based disturbance compensation method. For this purpose, the table acceleration is estimated using a dynamical model of the drive train and compared to the signal from an additional acceleration sensor attached to the machine table. Based on the resulting difference, an additional compensation torque is provided, which suppresses the disturbance in counterphase. The approach is tested experimentally on an open control platform with industrial drive components and the behavior is investigated based on compliance frequency responses and externally applied milling forces. At the same time, a standardized parametrization methodology is developed and the robustness is evaluated by varying table masses. In summary, a considerable improvement of the dynamic disturbance behavior can be achieved compared to the conventional system without compensator.
\end{abstract}

Keywords Rack-and-pinion drives $\cdot$ Disturbance compensation $\cdot$ Feedback control $\cdot$ Milling

\section{Introduction}

The achievable productivity and machining accuracy of modern machine tools and manufacturing systems is essentially determined by the dynamic properties of the feed drive systems used. These determine the achievable drive force and acceleration and the positioning accuracy as well as the static and dynamic stiffness characteristics of the individual machine axes [3]. Consequently, position-controlled feed drive systems are a key component of the modern manufacturing industry. Nowadays, the motion of the individual machine axes is generated by the use of linear direct drives and electromechanical feed drives [2]. In the latter case, the rotary motion of the highly dynamic motors is converted into a linear motion of the machine table, with ball screw drives or rack-and-pinion drives (RPD) usually being used

Felix Brenner

felix.brenner@isw.uni-stuttgart.de

1 University of Stuttgart, Institute for Control Engineering of Machine Tools and Manufacturing Units (ISW), Seidenstrasse 36, Stuttgart 70174, Germany as mechanical transmission elements. Due to the excellent cost-performance ratio, the high positioning accuracy as well as a low assembly and maintenance requirements, ball screw drives are still the main drive solution in the machine tool industry. However, from a feed length of about 4-5 m, the gradually increasing spindle diameter leads to a large inertia increase, which is accompanied by a reduction in the drive dynamics [9]. Since ball screw drives can no longer be operated efficiently above such feed lengths, RPDs are used in particular for large machine tools [29].

\subsection{Rack-and-pinion drive control}

Today, position-controlled feed drive systems are almost exclusively operated through a cascade structure with subordinate proportional-integral (PI) current and speed control as well as proportional $(\mathrm{P})$ position control [25]. The controlled values of the individual cascades are fed back separately, whereby the dynamics of the individual control loops decrease from the inside to the outside. Essential for the achievable accuracy and stiffness is the type of measuring system used within the position control loop, see Fig. 1. 


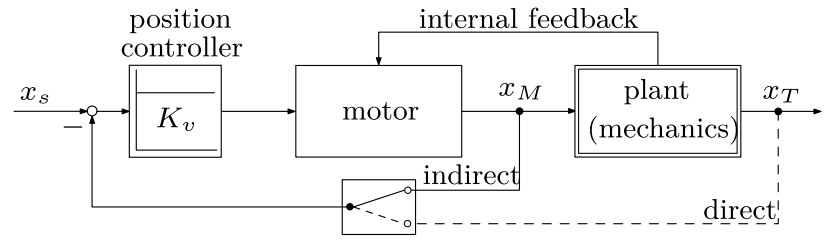

Fig. 1 Direct and indirect position control of rack-and-pinion drives

While direct positioning measurement systems on the table side are widely used for compact and high-precision machine tools, indirect position signals are often used as controlled value for large machine tools with rack-and-pinion drives. In this case, the table position $x_{T}$ is determined indirectly based on the motor encoder $x_{M}$ and the known transmission ratios [32]. By omitting the additional direct measuring system, great cost advantages can be achieved. Here, not only the acquisition costs themselves, but also the integration costs, which arise due to the increasingly complex alignment with long feed distances, must be included in the overall economic calculation. In addition, there is a probability of $15 \%$ that machine failures are due to measuring system errors [20], making indirect position control loops still widespread despite the falling costs of the linear scales themselves. However, a central problem of indirect position control loops is the unavailability of table-sided state informations. This means that the system can only react inadequately to disturbance variables that are outside the control loop, resulting in an overall reduction in positioning accuracy and disturbance stiffness. In addition to processrelated load forces, friction forces typically occur as disturbance variables within the machine axes, which are usually characterized by a pronounced nonlinearity.

\subsection{Disturbance compensation in drive systems}

Considering the constantly increasing accuracy requirements for modern machine tools, additional actions have to be taken to improve the dynamic tracking and disturbance behavior of indirectly controlled rack-and-pinion drives. In particular, compensating control loops, which extend the conventional cascade control, provide considerable potential for dynamic improvement $[21,23]$. For the realization of such structures, acceleration sensors mounted on the table side are particularly suitable. These can be used to detect the vibration state of the feed axis on the output side even without a direct position measuring system. However, the currently existing approaches of acceleration-based compensators mainly focus on ball screws and linear direct drives with additional direct measurement of the table position [7, 13, 17].

For ball screws drives, an additional speed control loop for the mechanics with a Ferraris sensor has been researched, which increases the bandwidth within the postion control loop [22]. In addition, compensation modules have already been developed for directly controlled ball screws drives $[4$, 14] and linear direct drives [28], which provide compensating reference values on the position and velocity level. On top of that, there are control loops on the force or current level $[16,18]$, which can be used to compensate disturbances in a highly dynamic manner.

In contrast, there are only a few approaches for indirectly controlled rack-and-pinion drives. In the method presented in [19], the table acceleration is fed back into the velocity control loop on the motor side via a complex filter structure, thus, the compensation does not take place directly at the current or force level. Furthermore, there are two approaches [15] and [5] where the compensation is applied directly on the current level, but the elasticity of the oscillatory mechanics is neglected. This results in a relatively small useful frequency range of the methods.

This paper is intended to fill the gap of the already existing approaches by developing a highly dynamic compensation method on the current respectively force level, which will simultaneously capture the influence of the dynamic-limiting mechanics. After a theoretical derivation of the method on the basis of a generally valid drive model (Sect. 2), the mode of action is confirmed by numerous experimental investigations. Particular attention will be paid to the dynamic disturbance behavior, which will be evaluated on the one hand by investigating compliance frequency responses and on the other hand by applying milling forces (Sect. 3). In addition, a standardized parameterization scheme is presented and the robustness of the method is finally evaluated.

\section{Disturbance compensation design}

The dynamic transfer behavior of rack-and-pinion drives results from the interaction of the individual subcomponents of the drive train. Due to today's modern servo and inverter technology, very high current control bandwidths are usually achieved, so that the mechanical transfer behavior is the limiting factor compared to the electrical subsystem. The coupled mechanical transmission behavior can basically be described by multi-mass oscillator systems with a large number of degrees of freedom (DOF). Typically, the lowest natural frequency occurring in the drive train has the dominant influence and limits the achievable bandwidth of the position control [12]. The starting point for the design of the acceleration-based disturbance compensation is thererfore a simplified two-mass oscillator model [24], which is used to abstract the dynamic transfer behavior in a modelbased manner by capturing the first natural frequency [8], see Fig. 2. 


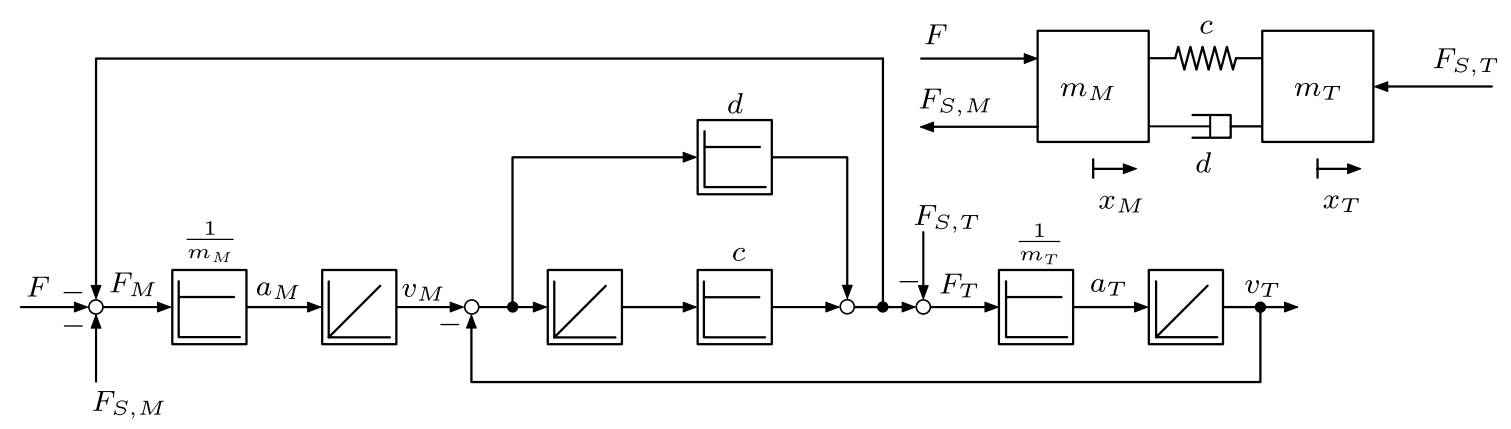

Fig. 2 Signal flow diagram of a 2-mass oscillator

The feed drive system is composed of a rotational equivalent mass $m_{M}$ (motor, gearbox, pinion) and a translational moving mass $m_{T}$, whereby the elasticity is captured via the stiffness and damping constants $c$ and $d$. The addtional gearbox is often installed between the motor and the pinion shaft in order to generate high torques for the movement of the mostly large inertias. The conversion of all rotatory parameters into their translatory equivalence is carried out taking into account the transmission ratio of the the pinion radius $r$ and gearbox $i$. The driving force $F$ acting on the system results from the proportional relationship between torque constant $K_{M}$ and the torque-generating current $i_{q}$. The torque-generating current is available as a measurable signal in the frequency inverter due to the transformations performed on the electrical currents and the subordinate current control that is present anyway. Of central importance for the development of a compensating control loop is the dynamic transfer behavior of the driving force to the resulting table force $F_{T}$

$G_{E}(s)=\frac{F_{T}(s)}{F(s)}=\frac{1+s \frac{d}{c}}{1+s \frac{d}{c}+s^{2} \frac{m_{M} m_{T}}{\left(m_{M}+m_{T}\right) c}}$.

The transfer behavior is composed of a second-order low-pass filter with an additional zero. The latter can be neglected due to the often very low mechanical damping values [31], since the behavior in the relevant frequency range is dominated by the conjugate complex pole pair of the denominator

$G_{E}(s) \approx \frac{1}{1+s \frac{d}{c}+s^{2} \frac{m_{M} m_{T}}{\left(m_{M}+m_{T}\right) c}}$.

In addition to the existing friction forces, process-related load forces $F_{S, M} / F_{S, T}$ typically occur as disturbance variables in the drive train, which act on the drive motor as a feedback disturbance force. Since the drive immediately reacts to the introduced disturbance by applying an additional compensation torque, the input of the current control loop is the innermost and thus most dynamic point of intervention within the cascade control in order to implement a disturbance compensator. For this purpose, the acceleration $\hat{a}_{T}$ expected at the machine table is firstly estimated using the relationship established in eq. (2). In addition, the actual acceleration $a_{T}$ is measured via an accelerometer attached to the machine table. The difference between the measured and estimated acceleration can be used to obtain a synthesized current $i_{q, c}$, which is fed into the control cascade as an additional command value, see Fig. 3. The mode of operation of the compensation term is limited by an additional low-pass filter $G_{L P}$ with the filter cut-off frequency $f_{g}$ in the feedback path in order to attenuate the high-frequency noise effects occurring in the measured current and acceleration signal.

\section{Experimental results}

The disturbance compensation method developed in the previous section is implemented and evaluated for experimental studies on a rack-and-pinion test bench. Figure 4 shows the test bench, which can be used either in classic pre-loaded dual-motor mode or in single-motor mode [30]. In the present application, however, the second drive train is completely dismounted and the approach is initially evaluated for the case with only one drive. However, it should be noted that the method can in principle also be used for preloaded rack-and-pinion drives with a master-slave position control structure [11]. In addition to extensive measuring systems, an additional linear direct drive is integrated on the machine slide, which can be used to introduce table-side disturbance forces into the axis structure. The dimensioning and component selection of the test bench was based on common requirements in the machine tool area, see Table 1. The entire conventional cascaded drive control is implemented on the control unit (CU) of the servo control system, whereby the position control loop is operated at $1 \mathrm{kHz}$ and the speed, respectively, current control loop at $8 \mathrm{kHz}$. The individual control cascades were parameterized according to the usual setting rules in machine tool industry. For this purpose, the speed control loop was implemented 


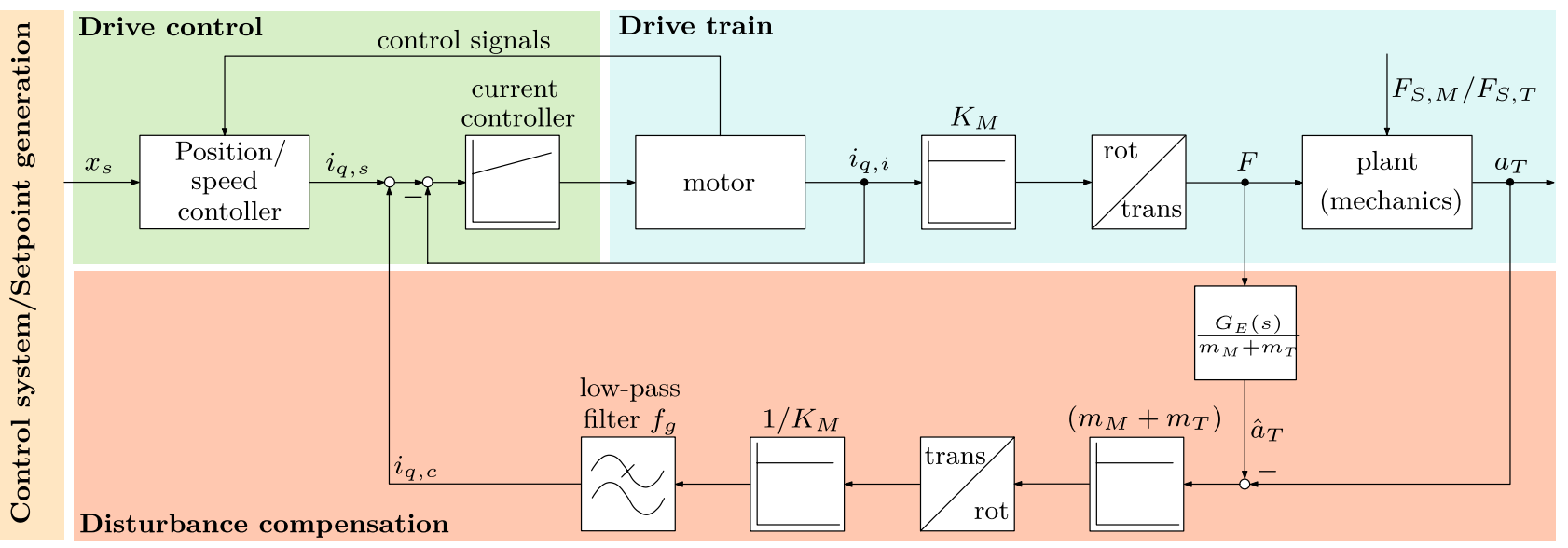

Fig. 3 Structure of the acceleration-based disturbance compensation

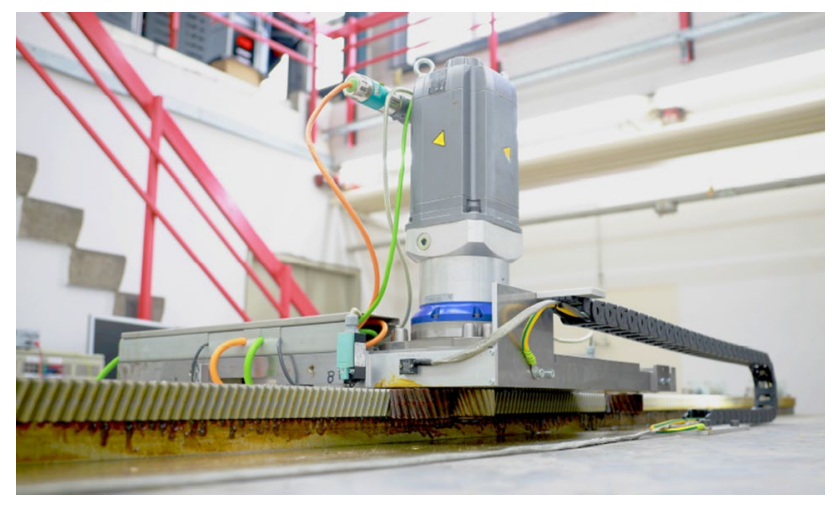

Fig. 4 Rack and pinion test bench

Table 1 Parameters of the test bench

\begin{tabular}{llll}
\hline Parameter & Variable & Value & Unit \\
\hline Gear ratio & $i$ & 16 & - \\
Pinion radius & $r$ & 42.44 & $\mathrm{~mm}$ \\
Torque constant & $K_{M}$ & 1.25 & $\mathrm{Nm} / \mathrm{A}$ \\
Drive mass & $m_{M}$ & 1067 & $\mathrm{~kg}$ \\
Table mass & $m_{T}$ & 420 & $\mathrm{~kg}$ \\
Nominal motor speed & $n_{N}$ & 4500 & $1 / \mathrm{min}$ \\
Nominal motor torque & $M_{N}$ & 12.5 & $\mathrm{Nm}$ \\
Position control gain & $K_{v}$ & 70.8 & $1 / \mathrm{s}$ \\
Speed control gain & $K_{p}$ & 6.65 & $\mathrm{Nms} / \mathrm{rad}$ \\
Speed control reset time & $T_{N}$ & 2.26 & $\mathrm{~ms}$ \\
\hline
\end{tabular}

using the symmetrical optimum and the position control loop was designed with regard to overshoot-free positioning (aperiodic case).

The disturbance compensation is implemented on a separate real-time system and is operated in the same cycle as the current control loop, see Fig. 5. The torque-generating motor

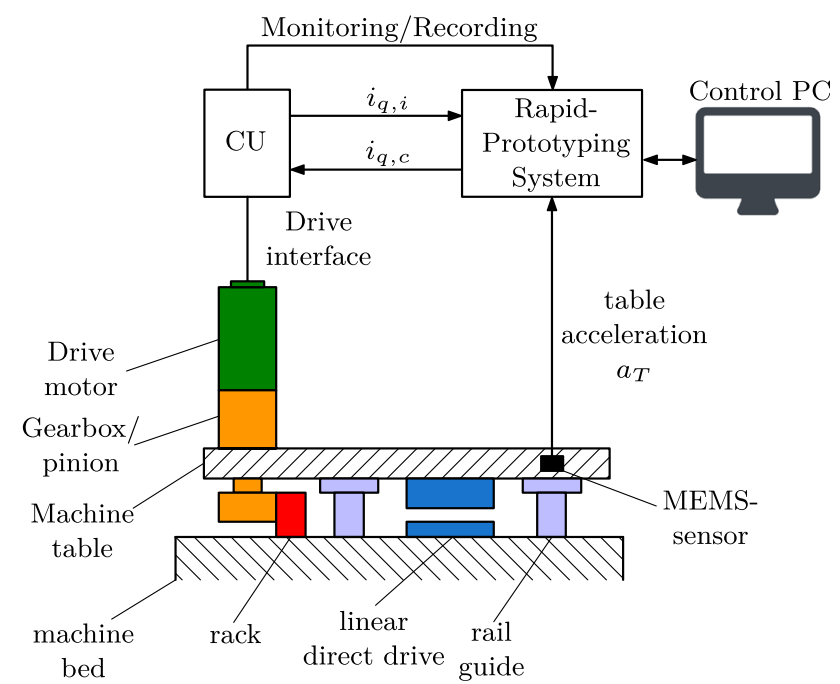

Fig. 5 Control architecture with rapid prototyping system

current and the externally connected acceleration sensor are processed analog via an FPGA board and are available on the real-time system with a sampling rate of $8 \mathrm{kHz}$. As an acceleration sensor, a compact and low-cost MEMS (micro electro mechanical system) sensor is used, which is rigidly attached to the machine table. Through an additional ProfiBUS module, all measured and controlled variables available on the CU can be accessed and monitored on the control PC. An overview of the components installed on the test bench is shown in Table 2.

\subsection{Parameterization of the disturbance compensation}

The application of the developed concept for disturbance compensation requires the parameterization of the two filter structures $G_{E}$ and $G_{L P}$. All remaining parameters such 
Table 2 Components of the test bench

\begin{tabular}{ll}
\hline Component & Factory number \\
\hline Motor & Synchronous motor siemens \\
& 1FT7086-5AH70-1CA0 (Drive Cliq) \\
Gearbox & Planetary Gear Wittenstein RP040S \\
Pinion & Wittenstein RMT400 \\
Linear direct drive & Siemens 1FN3300 \\
Acceleration sensor & Capacitive MEMS Accelerometer \\
& Kistler 8315A010D0AC10 \\
Encoder & Absolute Encoder Siemens AM24DQI \\
Direct position measuring & Schneeberger SSI AMSABS3 \\
system & \\
\hline
\end{tabular}

as the pinion radius, the gear ratio, the motor constant and the inertias in the drive train can be taken from the corresponding data sheets of the components. The parameters for stiffness and damping $(c, d)$ in the feed direction contained in the elastic transfer function $G_{E}$ can either be estimated approximately on the basis of the mechanical properties of the rack-and-pinion drive or obtained via a frequency response analysis. For the second case, the mechanical frequency response can be used, which characterizes the dynamic transfer behavior from the motor speed $v_{M}$ to the table speed $v_{T}$ and can be measured as standard in many drive units. If the mechanical frequency response for the already described two-mass oscillator model is set up

$G_{M}(s)=\frac{v_{T}(s)}{v_{M}(s)}=\frac{1+s \frac{d}{c}}{1+s \frac{d}{c}+s^{2} \frac{m_{T}}{c}}$

and the occurring zero is equally neglected due to the low mechanical damping

$G_{M}(s) \approx \frac{1}{1+s \frac{d}{c}+s^{2} \frac{m_{T}}{c}}$,

it can be seen that the mechanical transmission behavior can be approximated as a second-order delay element with conjugate complex pole pairs

$G(s)=\frac{\omega_{0}^{2}}{s^{2}+2 D \omega_{0} s+\omega_{0}^{2}}$.

Using a corresponding coefficient comparison, the mechanical stiffness and damping can be determined from the damping ratio $D$ and the characteristic frequency $\omega_{0}$, see Table 3 .

Figure 6 compares the real mechanics frequency response to the described model-based approximation. If the normalized root-mean-square deviation (NRSME)
Table 3 Identified mechanical parameters of the test bench

\begin{tabular}{llll}
\hline Parameter & Variable & Value & Unit \\
\hline Damping ratio & $D$ & 0.17 & - \\
Characteristic frequency & $\omega_{0}$ & 352 & $\mathrm{rad} / \mathrm{s}$ \\
Stiffness constant & $c$ & $5.1998 e+07$ & $\mathrm{~N} / \mathrm{m}$ \\
Damping constant & $d$ & $5.0245 e+04$ & $\mathrm{Ns} / \mathrm{m}$ \\
\hline
\end{tabular}

$\xi=1-\frac{|y-\hat{y}|}{|y-\operatorname{mean}(y)|}$

is used as a performance criterion for the degree of model accuracy, the model shows an overall fit of $76.2 \%$ in the frequency range up to about $100 \mathrm{~Hz}$. The performance value results from an error comparison, normalized to the mean value, between the actual output $y$ and the estimated output $\hat{y}$. Only in the higher frequency range up to $250 \mathrm{~Hz}$ the model shows a deviating behavior due to the existing resonanceabsorber phenomenon. This can be seen as the feedback effect of an additional vibration element on the table mass and is accompanied by a temporary phase increase in the phase response. To capture such effects, the introduced twomass model would have to be extended by additional degrees of freedom.

Since the bandwidth of the method is limited anyway by the low-pass behavior in the forward path for estimating $\hat{a}_{T}$ with the transfer function $G_{E}$, the bandwidth of the synthesized current $i_{q, c}$ is limited to the same frequency range. As a practical parameter, the $-3 \mathrm{~dB}$ cutoff frequency $f_{-3 \mathrm{~dB}}$ of the transfer function is used and equated with the cutoff frequency of the lowpass filter, see Fig. 7. This results in a filter cutoff frequency of $f_{g}=99.6 \mathrm{~Hz}$. For the present application, low-order infinite impulse response (IIR) filters have proved particularly useful. Compared to the otherwise
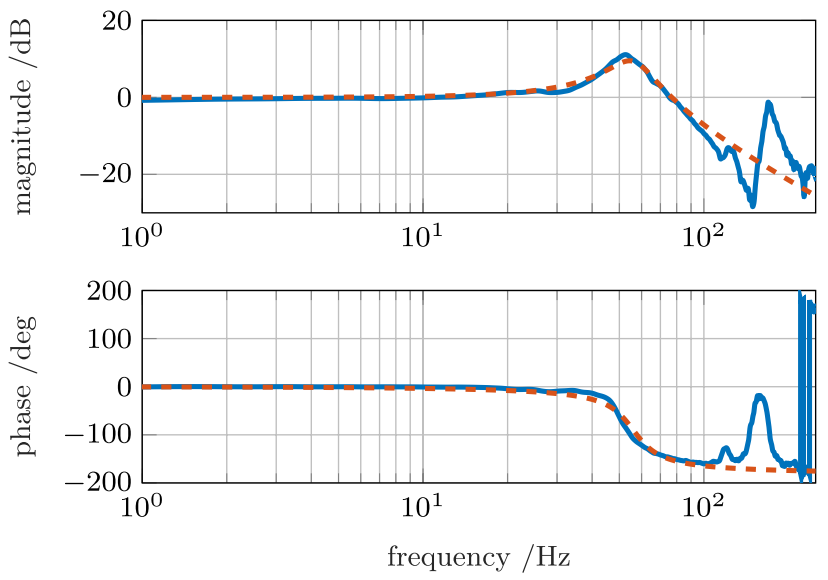

Fig. 6 Mechanical frequency response with PT2 approximation to determine stiffness and damping parameters 


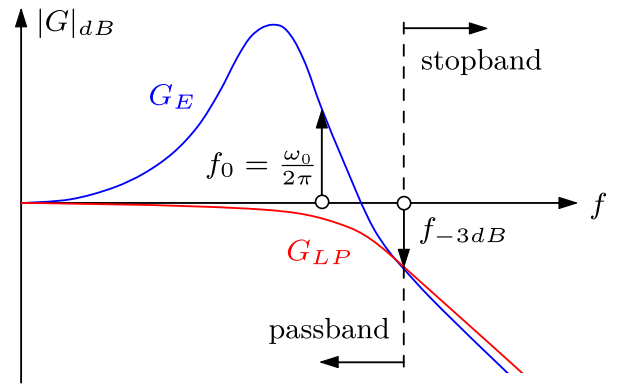

Fig. 7 Parameterization of the low-pass filter for the disturbance compensation

widespread FIR filters (finite impulse response), this is due to the relatively low time delay of the filter response, which makes it possible to generate a drive torque in counterphase to the disturbance variable. The IIR filter type used is a Bessel filter [27] with a low filter order of $n=2$. The Bessel filter used is characterized by a low phase shift in the relatively small effective frequency range and by a smooth frequency response in the passband. Finally, it should be noted that in principle also other (IIR) filter types can be used.

\subsection{Compliance behavior}

Due to the acceleration measurement of the machine table, the developed disturbance compensation is primarily used to specifically suppress disturbance forces occurring on the drive side. For the evaluation of the disturbance behavior, the dynamic compliance

$G_{c}(s)=\frac{x_{s}-x_{T}}{F_{S, T}}$

is to be considered. It is the complex coefficient of a displacement and the dynamic force $F_{S, T}$ [32]. Consequently, the dynamic compliance describes the frequency-dependent reciprocal value of the stiffness of a controlled electromechanical system. For the measurement-based frequency response analysis, a sine sweep of constant force amplitude and increasing frequency is applied to the linear direct drive and the resulting difference between the reference position $x_{s}$ and the table position is determined

$e(t)=x_{s}(t)-x_{T}(t)$.

Figure 8 shows the compliance frequency responses of the RPD with and without disturbance compensation. Due to the closed position control loop on the motor side, the rack-andpinion drive has only a low overall static stiffness $(f=0 \mathrm{~Hz})$ compared to systems with a direct position measuring system. Regarding the latter case, the static stiffness depends mainly on the linear measurement system used [8]. On the

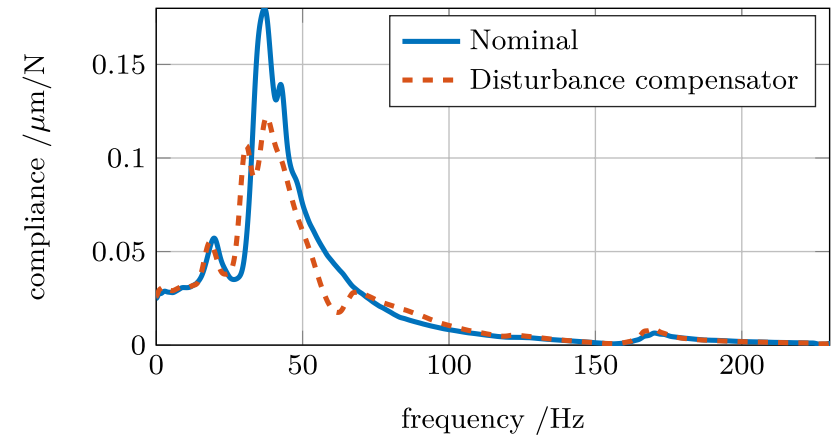

Fig. 8 Averaged compliance frequency responses

other hand, there is a visible maximum in the range of the first natural frequency. From this, it can be concluded that disturbance forces with a high spectral proportion in the range of the first natural frequency lead to a strong excitation of the drive system. Since the developed disturbance compensation generates a drive torque that is in counterphase to the disturbance force and thus compensates it significantly faster than conventional control, this leads to a considerable increase in damping. Due to the limited operating range of the disturbance compensation, the two compliance frequency responses match above the cutoff frequency of the low-pass filter. The compliance frequency responses shown in the figure were averaged over 18 frequency responses at different axis positions to remove measuring uncertainties. In contrast to the assumption of a position-independent behavior of rack-and-pinion drives which is often found in the literature $[6,29]$, the experimental results show that the local contact conditions of the engaged rack-and-pinion pair cause a certain spread of the results. Figure 9 illustrates the maximum dynamic compliance $N_{\max }$ in relation to the axis position. Despite the existing spread, the additional disturbance compensation reduces the maximum compliance occurring in the drive train at all positions in comparison to the conventional system.

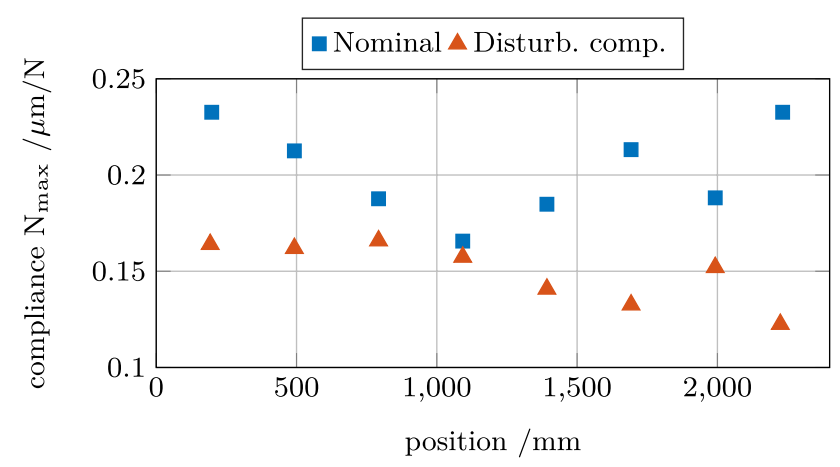

Fig. 9 Position-dependent maximum compliance $N_{\max }$ 


\subsection{Milling forces}

In order to verify the practical usability of the developed compensation method in an industrial environment, the behavior during the application of milling forces will be investigated. For this purpose, a standard 2-DOF milling force model [1] is implemented on the real-time system with configurable process parameters, which is used to control the linear direct drive. Since significantly higher disturbance forces are caused in peripheral milling compared to face milling due to the same direction of all force vectors, the critical case of peripheral milling in the feed direction will be addressed below. The process force of a single cutting edge of the milling cutter

$$
F_{P}\left(\varphi, a_{p}\right)=f(\varphi)\left(-F_{t}\left(\varphi, a_{p}\right) \cos (\varphi)-F_{r}\left(\varphi, a_{p}\right) \sin (\varphi)\right)
$$

is composed of a cutting force

$F_{t}\left(\varphi, a_{p}\right)=a_{p} k_{c} h_{z}(\varphi)^{1-m_{c}}$

and a radial force

$F_{r}\left(\varphi, a_{p}\right)=a_{p} k_{n} h_{z}(\varphi)^{1-m_{n}}$,

whereby the infeed depth is captured via the parameter $a_{p}$. The Heaviside function $f$, which depends on the cutter geometry, indicates whether the cutting edge is in engagement

$f(\varphi)= \begin{cases}1 & \text { if intervention, } \\ 0 & \text { otherwise }\end{cases}$

The chip thickness

$h_{z}(\varphi)=f_{z} \sin (\varphi)$

contained in the partial forces depends on the current rotational angle of the cutter $\varphi$ and the feed per tooth $f_{z}$. The remaining parameters for the specific cutting force $k_{c} / k_{n}$ and the material constants $m_{c} / m_{n}$ in eqs. (10) and (11) are material-dependent cutting parameters and can be taken from tables, thus they will not be discussed further $[10,26]$. Taking into account the number of cutting edges $n$ of the cutter and the corresponding angular offset between the individual cutting edges $\Delta \phi$, the total force acting in the feed direction can finally be calculated as

$F_{s}\left(\varphi, \Delta \phi, a_{p}\right)=\sum_{k=0}^{n-1} F_{P}\left(\varphi+k \Delta \phi, a_{p}\right)$.

As an application scenario, a $2 \mathrm{~m}$ long, $3 \mathrm{~mm}$ deep and $30 \mathrm{~mm}$ wide material removal is to be considered, with a cutting speed of $150 \mathrm{~m} / \mathrm{min}$ at a feed rate of $390 \mathrm{~mm} / \mathrm{min}$. All parameters used for the milling force model are presented in Table 4 . The choice of the mentioned parameters is based on
Table 4 Process parameters of the generated milling force

\begin{tabular}{llll}
\hline Parameter & Variable & Value & Unit \\
\hline Groove length & $l$ & 2000 & $\mathrm{~mm}$ \\
Cutting speed & $v_{c}$ & 150 & $\mathrm{~m} / \mathrm{min}$ \\
Infeed & $a_{p}$ & 3 & $\mathrm{~mm}$ \\
Width of engagement & $a_{e}$ & 30 & $\mathrm{~mm}$ \\
Cutting edge number & $n$ & 3 & - \\
Feed rate & $v_{F}$ & 390 & $\mathrm{~mm} / \mathrm{min}^{2}$ \\
Specific cutting force & $k_{c}$ & 1717 & $\mathrm{~N} / \mathrm{mm}^{2}$ \\
& $k_{n}$ & 928 & $\mathrm{~N} / \mathrm{mm}^{2}$ \\
Material constant & $m_{c}$ & 0.23 & - \\
& $m_{n}$ & 0.39 & - \\
\hline
\end{tabular}
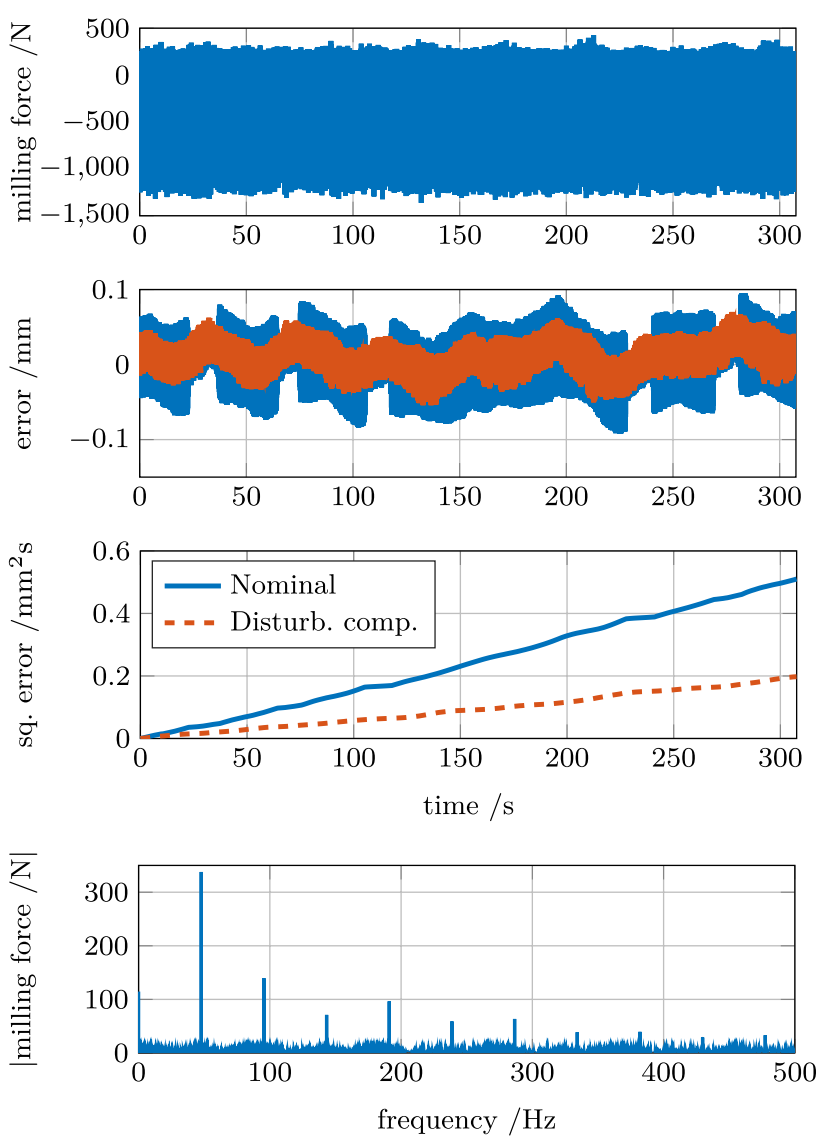

Fig. 10 Behavior in case of milling forces introduced via the linear direct drive with corresponding single-sided spectrum of the milling force

reference values from table books [10] (low strength steels, milling with carbide). The process force resulting from the milling force model for the application described is shown in Fig. 10. The generated milling force leads to a broadband excitation of the drive system, which can be recognized, by the additionally shown one-sided spectrum of the milling force. 
Furthermore, the error curve on the output side according to eq. (8), as well as the resulting quadratic error summation

$J_{s}=\int_{0}^{t_{f}} e(t)^{2} \mathrm{~d} t$

over the duration of the milling process $t_{f}$ is shown. As shown in the figure, the use of an additional accelerationbased disturbance compensator contributes to a significant reduction of the output side positioning error.

In addition to the objective of increasing accuracy, the efficiency of drive systems is becoming equally important. For this reason, the electrical energy consumption

$E=\int_{0}^{t_{f}} P(t) \mathrm{d} t$

via the integral of the absorbed power $P$ of the electric motor as well as the mechanical load [8]

$B=\int_{0}^{t_{f}}|M(t)|^{3}|\dot{\phi}(t)| \mathrm{d} t$

should also be taken into account. The latter is related to the wear and thus the durability of the feed drive system and is calculated via the motor torque $M$ acting on the drive system as well as the angular velocity oft the motor $\dot{\phi}$. As shown in Table 5 with the listed performance indicators, the use of the disturbance compensator contributes to a significant increase in efficiency. The electrical power consumption of the motor is reduced by the counterphase compensation, since the cascaded drive controller has to operate less against the disturbance variables that occur. Additionally, the mechanical load to the drive system is reduced due to the damping effect, which leads to a reduction in the acceleration peaks.

\subsection{Robustness analysis}

The key problem of many control concepts for increasing the dynamics of electromechanical feed drive systems is that they have insufficient robustness properties. Consequently, the robustness of the method will finally be evaluated. For this purpose, a practical scenario is to be used in which the mass of the machine table is being varied. This occurs, for example, when machining a large-volume component, which can cause significant mass changes. The mass change of the

Table 5 Performance characteristics during milling forces

\begin{tabular}{lll}
\hline & Nom. & Disturb. comp. \\
\hline Sq. error $J_{s}\left(\mathrm{~mm}^{2 \mathrm{~s}}\right)$ & 0.510 & $0.195(-61.8 \%)$ \\
El. Energy $E(W h)$ & 4.857 & $2.638(-45.8 \%)$ \\
Load $B\left(\mathrm{Nm}^{3 \mathrm{rad} / s}\right)$ & 3435.55 & $1040.32(-69.8 \%)$ \\
\hline
\end{tabular}

workpiece clamped on the machine table with the associated variation of the system dynamics is defined as a varying operating condition in the following.

This is accomplished by adding an additional mass of approximately $+130 \mathrm{~kg}$ to the existing test bench, so that the total table mass corresponds to $\tilde{m}_{T}=550 \mathrm{~kg}$. Subsequently, the cascade control is parameterized according to the usual setting rules and the distrubance compensation control loop is adjusted according to the guidelines presented in Sect. 3 . Using the test brench configured in this way, the milling tests as well as the compliance evaluation are repeated and the results with and without the compensator are compared. Next, the table mass is loaded $(+24 \%)$ or reduced $(-24 \%)$ by a further $\pm 130 \mathrm{~kg}$. The same series of measurements are then performed for both configurations, with both the control and compensator settings remaining unchanged. The results obtained from the described measurement methodology are shown for all three mass configurations in Fig. 11. In addition, Table 6 shows the performance characteristics for the tracking behavior and efficiency resulting from the milling scenario.

Based on the compliance frequency responses and the control errors, it can first be concluded that the increasing table mass in the drive train has a generally positive effect on the disturbance behavior. The gradually increasing damping effect can be seen both from the progressively reduced compliance and also in the reduction of the squared error norms. With respect to the disturbance compensation, it is shown that despite the incorrectly adjusted compensator, a significant improvement can be achieved for both a positive and a negative variation of the table mass. Depending on the table mass, the compensator achieves a reduction of the squared error norm from $49.7 \%$ to $60.0 \%$ compared to the nominal system. Equally, the compensator continues to improve the efficiency parameters at all operating points in terms of electrical energy consumption and mechanical load. In summary, it can be concluded that the method has promising robustness properties and contributes to a holistic improvement of the disturbance behavior even in different operating conditions with varying mass parameters.

\section{Conclusion}

In this paper, a highly dynamic disturbance compensation for indirectly controlled rack-and-pinion drives was developed and its performance was experimentally validated. The presented method bridges the gap to the already existing approaches, since both the elasticity of the drive system is considered as well as the compensation is simultaneously performed on the current level. The results show that considerable improvement of the dynamic disturbance behavior can be achieved. This is shown on the one hand in the 

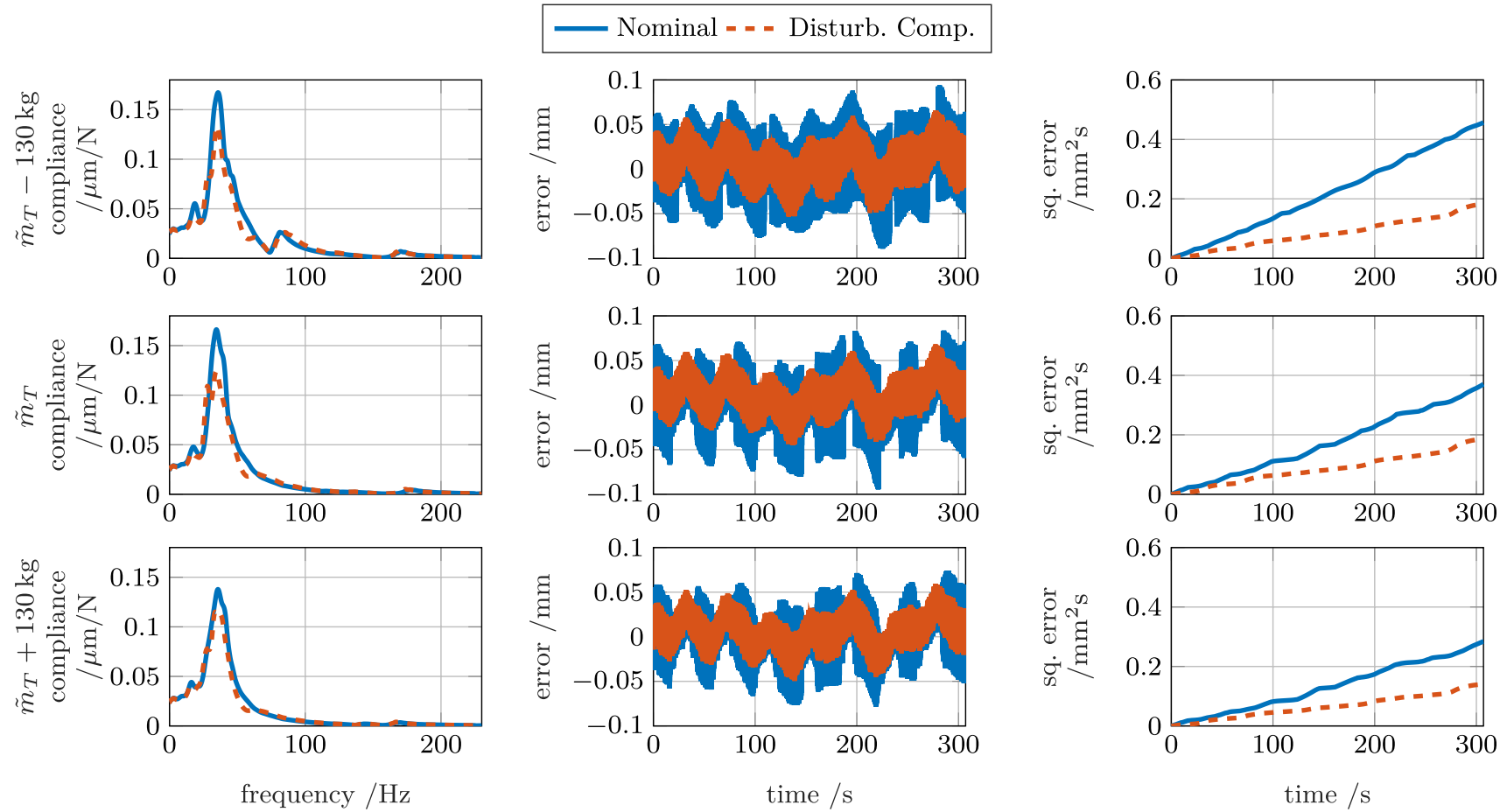

Fig. 11 Robustness with varying table mass (compliance \& milling force)

Table 6 Performance characteristics during milling forces and varrying table mass

\begin{tabular}{llll}
\hline & & Nom. & Disturb. comp. \\
\hline$-130 \mathrm{~kg}$ & Sq. error $J_{s}\left(\mathrm{~mm}^{2 \mathrm{~s}}\right)$ & 0.458 & $0.183(-60.0 \%)$ \\
& El. Energy $E(W h)$ & 4.544 & $2.732(-39.39 \%)$ \\
& Load $B\left(\mathrm{Nm}^{3 \mathrm{rad} / \mathrm{s}}\right)$ & 2995.17 & $1186.86(-60.4 \%)$ \\
$\tilde{m}_{T}$ & Sq. error $J_{s}\left(\mathrm{~mm}^{2 \mathrm{~s}}\right)$ & 0.372 & $0.187(-49.7 \%)$ \\
& El. Energy $E(W h)$ & 4.064 & $2.488(-38.8 \%)$ \\
$+130 \mathrm{~kg}$ & Load $B\left(\mathrm{Nm}^{3 \mathrm{rad} / \mathrm{s}}\right)$ & 2944.02 & $1350.10(-54.1 \%)$ \\
& Sq. error $\left.J_{s}(\mathrm{~mm})^{2 \mathrm{~s}}\right)$ & 0.284 & $0.141(-50.4 \%)$ \\
& El. Energy $E(W h)$ & 3.910 & $2.494(-36.2 \%)$ \\
& Load $B\left(\mathrm{Nm}^{3 \mathrm{rad} / \mathrm{s}}\right)$ & 2843.95 & $1359.33(-52.2 \%)$ \\
\hline
\end{tabular}

reduction of the maximum compliance occurring in the drive train and on the other hand in the reduction of the position error on the output side while applying milling forces. At the same time, the method has a positive effect on the efficiency of the feed drive system, as both the mechanical load and the electrical energy consumed are reduced. Furthermore, the method shows robust behavior in different operating conditions.

The implementation of the method requires the presence of an acceleration sensor mounted to the machine table. In addition, the torque-generating current of the drive is required, which, however, is available as a sensor signal on the inverter for the underlying current control. For a robust performance with counterphase disturbance suppression, the compensation must be operated in the highly dynamic current control cycle, thus the requirements for the computing and signal processing hardware must be considered demanding. In contrast to this, however, there is the relatively low complexity of the compensation algorithm itself, which can be realized via a relatively small number of elementary operations with two additional filter structures. The parameterization of the compensation method follows a standardized procedure based on a frequency response analysis and the data sheet values of the components that are available anyway.

In a further step, the improvement potential of the method will be evaluated in real milling applications. At the same time, the model for estimating the table acceleration will be extended by including higher-frequency effects such as absorber resonance phenomena. On top of that, further robustness investigations will be carried out for varying model parameters.

Acknowledgements This work was funded by the Deutsche Forschungsgemeinschaft (DFG, German Research Foundation), Project No. 271104968. The authors gratefully acknowledge the support by DFG. 


\section{Funded by DFG \\ Deutsche Forschungsgemeinschaft German Research Foundation}

Funding Open Access funding enabled and organized by Projekt DEAL.

\section{Declaration}

Conflict of interest The authors declare that they have no conflict of interest.

Open Access This article is licensed under a Creative Commons Attribution 4.0 International License, which permits use, sharing, adaptation, distribution and reproduction in any medium or format, as long as you give appropriate credit to the original author(s) and the source, provide a link to the Creative Commons licence, and indicate if changes were made. The images or other third party material in this article are included in the article's Creative Commons licence, unless indicated otherwise in a credit line to the material. If material is not included in the article's Creative Commons licence and your intended use is not permitted by statutory regulation or exceeds the permitted use, you will need to obtain permission directly from the copyright holder. To view a copy of this licence, visit http://creativecommons.org/licenses/by/4.0/.

\section{References}

1. Altintas Y, Stépán G, Merdol D, Dombóvári Z (2008) Chatter stability of milling in frequency and discrete time domain. CIRP J Manuf Sci Technol 1(1):35-44

2. Altintas Y, Verl A, Brecher C, Uriarte L, Pritschow G (2011) Machine tool feed drives. CIRP Ann. 60(2):779-796

3. Brecher C, (2002) Vergleichende Analyse von Vorschubantrieben für Werkzeugmaschinen. Dissertation, RWTH Aachen

4. Brecher C, Weck M, Yamasaki T (2006) Controller-integrated predictive oscillation compensation for machine tools with parallel kinematics. Int J Mach Tools Manuf 46(2):142-150

5. Brenner F, Lechler A, Verl A (2021) Störgrößenkompensation für Vorschubantriebe. wt Werkstattstechnik online 111(1):82-87

6. Choi Y, Choi E, Jang S, Park H, Ha J, (2006) Vibration analysis and dynamic optimization of a rack and pinion typed feed drive system for a router machine. In: ICMIT 2005: control systems and robotics, international society for optics and photonics, vol 6042, p 60424I

7. Doenitz S, (1999) Comparison of disturbance suppression for servo drives. In: 8th European conference on power electronics and applications, pp P-1

8. Engelberth T, (2020) Adaptive Verspannung von ZahnstangeRitzel-Antrieben. Dissertation, Universität Stuttgart

9. Engelberth T, Apprich S, Friedrich J, Coupek D, Lechler A (2015) Properties of electrically preloaded rack-and-pinion drives. Prod Eng 9(2):269-276

10. Fischer U, Gomeringer R, Heinzler M, Kilgus R, Näher F, Oesterle S, Paetzold H, Stephan A, (2010) Mechanical and metal trades handbook. Europa Lehrmittel
11. Franco O, Beudaert X, Erkorkmaz K (2020) Effect of rack and pinion feed drive control parameters on machine tool dynamics. J Manuf Materials Process 4(2):33

12. Frey S, Dadalau A, Verl A (2012) Expedient modeling of ball screw feed drives. Prod Eng 6(2):205-211

13. Iwasaki M, Shibata T, Matsui N (1999) Disturbance-observerbased nonlinear friction compensation in table drive system. IEEE/ASME Trans Mechatron 4(1):3-8

14. Kamalzadeh A, Gordon DJ, Erkorkmaz K (2010) Robust compensation of elastic deformations in ball screw drives. Int J Mach Tools Manuf 50(6):559-574

15. Karim A, Lindner P, Verl A (2018) Control-based compensation of friction and backlash within rack-and-pinion drives. Prod Eng 12(5):589-596

16. Katsura S, Irie K, Ohishi K (2008) Wideband force control by position-acceleration integrated disturbance observer. IEEE Trans Ind Electron 55(4):1699-1706

17. Künzel S, Reichel T, Schäfers E, Uhlich A, (2003) Method and apparatus for damping mechanical oscillations of a shaft in machine tools, manufacturing machines and robots. Patent US6903529B2

18. Mitsantisuk C, Ohishi K, Urushihara S, Katsura S (2011) Kalman filter-based disturbance observer and its applications to sensorless force control. Adv Robot 25(3-4):335-353

19. Munoa J, Beudaert X, Erkorkmaz K, Iglesias A, Barrios A, Zatarain M (2015) Active suppression of structural chatter vibrations using machine drives and accelerometers. CIRP Ann 64(1):385-388

20. Munzinger C, Schopp M (2009) Steigerung der Verfügbarkeit durch Überlastbegrenzung und prozessparallele Last-und Verschleißüberwachung, Optilast. Apprimus, Aachen

21. Necsulescu D, De Carufel J, De Wit CC (1997) Investigation on the efficiency of acceleration feedback in servomechanism with friction. Dyn Control 7(4):377-397

22. Pritschow G, Eppler C, Lehner WD (2003) Ferraris sensor-the key for advanced dynamic drives. CIRP Ann 52(1):289-292

23. Schrijver E, van Dijk J (2000) On the design of robust disturbance observers for mechatronic systems. IFAC Proc Volumes 33(26):819-824

24. Schröder D, (2000) Intelligent observer and control design for nonlinear systems. Springer Science \& Business Media

25. Sun Z, Pritschow G, Zahn P, Lechler A (2018) A novel cascade control principle for feed drives of machine tools. CIRP Ann 67(1):389-392

26. Surmann T (2017) Simulation der Dynamik von Drehund Fräsprozessen. Technische Universität Dortmund, Habilitationsschrift

27. Thompson M (2006) Intuitive analog circuit design. Elsevier

28. Uhlmann E, Eßmann J, Wintering JH (2012) Design-and controlconcept for compliant machine tools based on controller integrated models. CIRP Ann 61(1):347-350

29. Uriarte L, Zatarain M, Axinte D, Yagüe-Fabra J, Ihlenfeldt S, Eguia J, Olarra A (2013) Machine tools for large parts. CIRP Ann 62(2):731-750

30. Verl A, Engelberth T (2018) Adaptive preloading for rack-andpinion drive systems. CIRP Ann 67(1):369-372

31. Verl A, Frey S (2012) Improvement of feed drive dynamics by means of semi-active damping. CIRP Ann 61(1):351-354

32. Weck M (2006) Werkzeugmaschinen 5: Messtechnische Untersuchung und Beurteilung, dynamische Stabilität. Springer-Verlag 